\title{
Comparison of Two Pour-On Formulations of Ivermectin against Gastrointestinal Worms, Fleas and Lice in Naturally Infected Stray Dogs
}

\author{
Froylán Ibarra-Velarde', Yolanda Vera-Montenegro1, Joaquín Ambía Medina², \\ Karla Sánchez-Peralta1, Pedro Ochoa Galván ${ }^{3}$ \\ ${ }^{1}$ Departamento de Parasitología, Facultad de Medicina Veterinaria y Zootecnia, Universidad Nacional \\ Autónoma de México, México, D.F., México \\ ${ }^{2}$ Laboratorio Salud Animal, México, D.F., México \\ ${ }^{3}$ Departamento de Génetica, Facultad de Medicina Veterinaria y Zootecnia, Universidad Nacional Autónoma de \\ México, México, D.F., México \\ Email: ibarraf@unam.mx
}

Received 31 October 2014; accepted 12 March 2015; published 18 March 2015

Copyright (C) 2015 by authors and Scientific Research Publishing Inc.

This work is licensed under the Creative Commons Attribution International License (CC BY).

http://creativecommons.org/licenses/by/4.0/

(c) (i) Open Access

\section{Abstract}

The aim of the present study was to evaluate the efficacy of two commercial pour-on ivermectin formulations against intestinal parasites (IP), fleas and lice in naturally infested stray dogs. Eighteen crossbreed dogs with eggs of IP as well as adult fleas and lice were included in the trial. On day 0 , the dogs were randomly divided into 3 groups of 6 animals each: a group receiving a single pour-on treatment with $0.5 \%$ ivermectin $(500 \mathrm{mcg} / \mathrm{kg})$, a group treated similarly with $0.2 \%$ ivermectin $(200 \mathrm{mg} / \mathrm{kg})$, and a control group. Fecal and skin analyses were carried out on days 0, 7, 14, 21 and 28 to determine the reduction of eggs and the number of fleas and lice. Weight gain was also measured on day 28. On day 30, the dogs were humanely sacrificed in order to count adult IP. Efficacy was measured as the percentage of the reduction of eggs per gram fecal mass (EPGF), of adult IP, fleas and lice relative to the control group. For the eggs of IP, ivermectin at $0.5 \%$ showed an efficacy of $100 \%$ against ascarids and $79 \%$ against Ancylostoma caninum. ivermectin at $0.2 \%$ removed $90.2 \%$ of the ascarids and $50.4 \%$ of $A$. caninum. For adult IP, the efficacy of $0.5 \%$ ivermectin against Toxocara canis and $A$. caninum was $100 \%$, and for $0.2 \%$ ivermectin it was $62.4 \%$ and $76.4 \%$ for $T$. canis and $A$. caninum, respectively. Both compounds were $100 \%$ effective against lice and $96 \%$ and $71.1 \%$ efficacious against fleas, respectively. However, neither treatment was effective against Dypilidium caninum. Weight gain in treated dogs was statistically different from that of the controls $(p<0.05)$. We concluded that $0.5 \%$ pour-on ivermectin showed better efficacy than $0.2 \%$ pour-on ivermectin in the reduction of eggs and adult intestinal parasites and fleas; it was similarly efficacious against lice. 


\section{Keywords}

\section{Ivermectin, Intestinal Worms, Fleas and Lice, Stray Dogs}

\section{Introduction}

Infections with intestinal parasites (IP), fleas and lice in dogs and cats are very common all over the world [1]. They are the major factors responsible for public health losses and some times for public health risks and causing zoonotic diseases in human and animals [2]-[4]. For instance, the cat flea Ctenocephalides felis is the cause of severe discomfort and irritation in humans, dogs and cats. It is also responsible for the production of allergic dermatitis [5]. This flea can also serve as the vector of typhus-like rickettsia and is the intermediate host for filarids and cestodes. In addition, fleas, being hematophagous insects, can produce iron deficiency anemia in heavy infestations, particularly in young animals. They have been reported to produce anemia in dogs, cats, goats, cattle and sheep [6]-[8]. Murine typhus, caused by the organism Rickettsia typhi, is a mild febrile disease characterized by the development of headaches, chills, and skin rashes in humans with an infrequent involvement oin the kidneys and the central nervous system [9]. With the increase in feline plague cases in the western US, there are some concerns over the importance of $C$. felis as a possible vector. Ctenocephalides felis serves as an intermediate host of the subcutaneous filarid nematode of dogs Dipetalonema reconditum [10].

On the other hand, macrocyclic lactones, such as avermectin and milbemycins, show a high anti-parasitic activity against nematodes, fleas and lice in dogs and many other animals. It is available in injectable, oral, or topical formulations for use in animals [11]-[13]. It is frequently used in combination with other drugs [14]-[17]. Nowadays, considering its wide spectrum of activity, it is one of the drugs most employed to control some helminths and artropods.

However, even though investigations with ivermectins on internal and external parasites in ruminants and horses are widely documented [18]-[22], the research on the efficacy of pour-on ivermectin formulations in dogs is somewhat scarce [3]-[23]. In Mexico, where disease-carrying IP, fleas and lice in dogs are abundant, no controlled test on the impact of pour-on ivermectin has been carried out, either on the weight differences of treated animals or on the specific identification of the parasites present before and after treatment of the dogs.

The aim of the present study is to compare the efficacy of two pour-on ivermectin formulations against IP, fleas and lice as well as the weight differences and specific identification of parasites in naturally infested stray dogs from Mexico.

\section{Materials and Methods}

Study design. In the present study, eighteen 5 to 12 month-old stray dogs (crossbreed) of both sexes and weights between 4 and $15 \mathrm{~kg}$ were selected on the basis of the high numbers of egg per gram of the faeces (EPGF) of intestinal parasites or adult fleas and lice.

Drugs. 1) Vermisan Pour-on ${ }^{\circledR}$ (Laboratorios Salud Animal, S.A de C.V) containing ivermectin at $0.5 \%$ for pour-on application.

2) Dermodex ${ }^{\circledR}$ (CPMax S.A de C.V.) containing ivermectin at $0.2 \%$ for pour-on application.

Conduction of the study. On day 0, the dogs were divided into 3 groups (G) of 6 animals each. They were individually caged to avoid inter group re-infestation. Group 1 (G1) received a single treatment with ivermectin at $0.5 \%$ applied percutaneously (pour-on) at $500 \mathrm{mg} / \mathrm{kg}^{-1}(1 \mathrm{ml} / 10 \mathrm{~kg}$ body weight).

G2 received a single treatment with ivermectin at $0.2 \%$ topically (pour-on) applied at $200 \mathrm{mg}^{-1} / \mathrm{Kg}(1 \mathrm{ml} / 10$ $\mathrm{kg}$ body weight), according to label instructions.

G3 served as a non-treated control.

Coprological analyses. Simple fecal analyses using the McMaster method was carried out on days 0 (day of treatment), 7, 14, 21 and 28 to determine the percentage of Egg Per Gram of Feces (EPGF).

The administration of any other anthelmintic drug was prohibited for the duration of the study.

Adverse events occurring before and after treatments were recorded for each individual animal. The study was strictly limited to the person preparing and administering the doses and other witnesses present for the preparationand administration of the doses were not permitted to be involved in any observation made as end 
points for the study e.g. fecal egg counts (FEC).

On day 30 after treatment, the dogs were humanely sacrificed using an overdose of sodium penthobarbital injected into the femoral vein. Once the dogs showed no vital signs, the necropsy was performed on each animal to obtain the intestine and to collect and identify the adult worms.All procedures were carried out with the approval of the Internal Comitee for Use and Care of Animals for Experimentation. In addition, the number of fleas and lice after treatment was also individually recorded to determine the percentage of ectoparasite reduction in all experimental groups. All identification procedures for parasites were carried out according to [10].

Drug efficacy and statistical analysis. Efficacy was measured as the percentage reduction in the EPGF, adult worms, as well as in the number of fleas and lice from the treated groups relative to the untreated control. To do this the following formula was used: [24] [25].

$\% \mathrm{R}=\mathrm{T} 1-\frac{\mathrm{T} 2}{\mathrm{~T} 1} \times 100$ where:

$\% \mathrm{R}=$ The percentage of reduction of $\mathrm{EPG}$, adult worms, fleas and lice.

$\mathrm{T} 1=$ The geometric mean of the control group.

$\mathrm{T} 2=$ The geometric mean of the treated group.

Differences on the weight gain. This parameter was also measured and aimed at determining if 30 days after a single treatment the dogs showed a statistical difference on the weight gain when compared with that of the non treated control group.

Statistical analysis. The information obtained was submitted to the Kruskall-Wallis test and the Wilcoxon sign test, using the Sientific Analysis System (S.A.S) paquet, 2004.

\section{Results}

Our parasitological procedures showed that most of the dogs were infested with Ancylostoma caninum, Toxocara canis and Dypilidium caninum.

Coprological analyses. At the beginning of the experiment (day 0), the average number of EPGF in the control group was 4900 and 12,900 for Toxocara and Ancylostoma, respectively.

The fecal analyses showed the presence of ascarids and Ancylostoma eggs, but not the presence of Dypilidium eggs (Table 1).

Drug efficacy at reducing parasite eggs. The efficacy conferred by ivermectin at $0.5 \%$ throughthe percentage of reduction of EPG against ascarids was $100 \%, 75.5 \%, 98.7 \%$ and $100 \%$, and for Ancylostoma $100 \%$, 87.5\%, $83.3 \%$ and $79 \%$, for days $7,14,21$ and 28 , respectively. When the efficacy of both drugs was statistically compared, significant differences were found viz. $\mathrm{p}<0.007, \mathrm{p}<0.049, \mathrm{p}<0.07$ and $\mathrm{p}<0.14$, for days 7, 14, 21 and 28, respectively (Table 1).

As it can be observed in Table 1, the efficacy exerted at the 7th. day post treatment is high $(100 \%)$ and it proportionally decreases as the following faecal analyses were carried out.

In the case of ivermectin at $0.2 \%$, the data obtained showed a lower efficacy since the percentages of ascarid reduction of EPG were 46.6\%, 100\%, 91.6\% and 90.2\% and for Ancylostoma 50.7\%, 47.1\%, 42.3\% and 50.4\%, respectively.

It can be said then that the efficacy exerted for both compounds in terms of EPG reduction can be considered similar against ascarids but lower against Ancylostoma in the case of Ivermecyin at $0.2 \%$. (Figure 1).

Drug efficacy against adult intestinal parasites. Specimens such as Dypilidium caninum, Taenia taeniaeiformis, Toxocara canis, Toxascaris leonina and Ancylostoma caninum were collected at necropsy (Figure 2).

The percentage of efficacy for ivermectin at $0.5 \%$ was $100 \%$ for $T$. canis and A. caninum. For ivermectin at $0.2 \%$ the efficacy obtained against adult worms was $62.4 \%$ for $T$. canis and $76.4 \%$, for A. caninum (Figure 3 ).

Statistical differences were determined with both formulations against $T$. canis $(\mathrm{p}<0.055)$ and A. caninum $(\mathrm{p}<$ 0.0073).

No evaluations against $T$. taeniaeiformis and T. leonina were carried out since very few specimens of these parasites were recorded (Figure 3 and Table 2).

Also no statistical analyses were performed with the data on Dypilidium since it was evident that no efficacy at all was exerted from both compounds against this cestode.

Efficacy against fleas and lice. The percentage reduction forivermectin at $0.5 \%$ on fleas was $67.9 \%, 78.8 \%$, $91.5 \%$ and $96 \%$ and for ivermectin at $0.2 \% 57.7 \%, 66.7 \%, 59.2 \%$ and $71.1 \%$, respectively. The statistical analysis showed significant differences betwen groups ( $\mathrm{p}<0.107),(\mathrm{p}<0.0076),(\mathrm{p}<0.0024)$ and $(\mathrm{p}<0.001)$ 
Table 1. Coprological analysis of Eggs Per Gram of Feces (EPGF) before and after pour-on treatment with ivermectin of dogs naturally infected with intestinal parasites.

\begin{tabular}{|c|c|c|c|c|c|c|c|c|c|c|c|c|c|}
\hline \multirow{3}{*}{$\begin{array}{l}\text { Groups } \\
(\mathrm{n}=6)\end{array}$} & \multirow{3}{*}{ Sex } & \multicolumn{6}{|c|}{ Day of treatment } & \multicolumn{6}{|c|}{ Days after treatment } \\
\hline & & \multirow[t]{2}{*}{ Weight } & \multirow{2}{*}{$\begin{array}{l}\text { Dose } \\
\text { (ml) }\end{array}$} & \multicolumn{2}{|c|}{0} & \multicolumn{2}{|c|}{7} & \multicolumn{2}{|c|}{14} & \multicolumn{2}{|c|}{21} & \multicolumn{2}{|c|}{28} \\
\hline & & & & Tox $^{*}$ & $\mathrm{Anc}^{* *}$ & Tox & Anc & Tox & Anc & Tox & Anc & Tox & Anc \\
\hline & M & 10 & 1 & 50 & 600 & 0 & 0 & 0 & 0 & 0 & 0 & 0 & 0 \\
\hline 1 & M & 6 & 0.6 & 150 & 300 & 0 & 0 & 0 & 0 & 0 & 0 & 0 & 0 \\
\hline \multirow[t]{4}{*}{$\begin{array}{c}\text { Ivermectin } \\
0.5 \%\end{array}$} & M & 4 & 0.4 & 650 & 1350 & 0 & 0 & 150 & 0 & 50 & 0 & 0 & 100 \\
\hline & $\mathrm{F}$ & 8 & 0.8 & 100 & 250 & 0 & 0 & 0 & 0 & 0 & 0 & 0 & 0 \\
\hline & $\mathrm{F}$ & 4 & 0.4 & 350 & 800 & 0 & 0 & 200 & 0 & 0 & 0 & 0 & 0 \\
\hline & $\mathrm{F}$ & 6 & 0.6 & 150 & 200 & 0 & 0 & 200 & 150 & 0 & 300 & 0 & 250 \\
\hline \multicolumn{4}{|c|}{ Total of EPGF/group } & 1450 & 3500 & 0 & 0 & 550 & 150 & 50 & 300 & 0 & 350 \\
\hline & $\mathrm{F}$ & 5 & 0.5 & 250 & 10,250 & 50 & 0 & 0 & 0 & 0 & 0 & 0 & 0 \\
\hline 2 & $\mathrm{~F}$ & 8 & 0.8 & 100 & 150 & 150 & 1500 & 100 & 1750 & 50 & 1150 & 50 & 800 \\
\hline \multirow[t]{4}{*}{$\begin{array}{c}\text { Ivermectin } \\
0.2 \%\end{array}$} & M & 4 & 0.4 & 150 & 650 & 0 & 100 & 0 & 0 & 0 & 0 & 0 & 0 \\
\hline & M & 6 & 0.6 & 300 & 1750 & 0 & 900 & 0 & 650 & 0 & 2150 & 0 & 1650 \\
\hline & $\mathrm{F}$ & 15 & 1.5 & 100 & 4450 & 150 & 29,100 & 0 & 8050 & 0 & 17,350 & 0 & 14,900 \\
\hline & M & 6 & 0.6 & 100 & 3500 & 100 & 1000 & 0 & 700 & 0 & 150 & 0 & 100 \\
\hline \multicolumn{4}{|c|}{ Total of EPGF/group } & 1000 & 20,750 & 450 & 32,600 & 100 & 11,150 & 50 & 20,800 & 50 & 17,450 \\
\hline & $\mathrm{F}$ & 4 & --- & 750 & 750 & 0 & 0 & 100 & 4350 & 0 & 1750 & 0 & 2400 \\
\hline 3 & M & 7 & --- & 100 & 550 & 50 & 0 & 200 & 50 & 150 & 500 & 0 & 9400 \\
\hline Untreated & M & 11 & -- & 100 & 800 & 250 & 50 & 850 & 100 & 50 & 3400 & 0 & 7100 \\
\hline \multirow[t]{3}{*}{ Control } & $\mathrm{F}$ & 3 & --- & 3500 & 9700 & 2400 & 350 & 50 & 3000 & 0 & 8100 & 0 & 1450 \\
\hline & M & 9 & --- & 350 & 350 & 2400 & 50 & 5050 & 50 & 5050 & 0 & 0 & 1750 \\
\hline & $\mathrm{F}$ & 11 & -- & 100 & 750 & 50 & 0 & 100 & 50 & 250 & 500 & 50 & 3600 \\
\hline \multicolumn{3}{|c|}{ Total of EPGF/group } & & 4900 & 12,900 & 5150 & 450 & 6350 & 7600 & 5500 & 14,250 & 50 & 25,700 \\
\hline
\end{tabular}

$1 \mathrm{ml}=20 \mathrm{drops}=200 \mathrm{mcg} / \mathrm{kg}$ de pv. ${ }^{*}=$ Toxocara canis; ${ }^{* *}=$ Ancylostoma caninum.

for days 7, 14, 21 and 28, respectively, clearly indicating that the efficacy produced by ivermectin at $0.5 \%$ on fleas was higher (Figure 4).

In the case of lice, both compounds showed $100 \%$ efficacy. Here it is important to mention that the number of lice was lower than the number of fleas; this might be one of the reasons why there were no statistical differences between groups.

\section{Discussion}

Ivermectin (IVM), a member of the macrocyclic lactone antiparasitic drugs, exhibits a broad spectrum in activity against gastrointestinal (GI) and lung nematodes as well as against ectoparasites of clinical relevance in domestic animals [17]. Since the IVM patent protection has expired, several "similar" (generic) products have entered the veterinary market worldwide; according to official data more than 60 different IVM formulations are currently registered for use in veterinary medicine [17]. However, pour-on presentations for the treatment of 
Table 2. Specific identification and percentage of endo and ectoparasites from specimens collected from the untreated control group.

\begin{tabular}{|c|c|c|c|c|}
\hline & & Endoparasites & & \\
\hline & & Specie & No. of specimens & Percentage (\%) \\
\hline \multirow{6}{*}{ 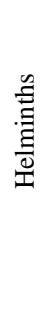 } & \multirow{3}{*}{ Cestodes } & Dypilidium caninum & 151 & 37.9 \\
\hline & & Taenia taeniaeformis & 1 & 0.2 \\
\hline & & Toxocara canis & 8 & 2 \\
\hline & \multirow[t]{3}{*}{ Nematodes } & Toxascaris leonina & 1 & 0.2 \\
\hline & & Ancylostoma caninum & 237 & 59.5 \\
\hline & & Total & 398 & \\
\hline \multirow{7}{*}{ 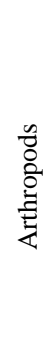 } & & Ectoparasites & & \\
\hline & & Ctenocephalides canis & 94 & 62.5 \\
\hline & Fleas & Ctenocephalides felis & 27 & 18.7 \\
\hline & \multirow{4}{*}{ Lice } & Pulex irritans & 8 & 5.5 \\
\hline & & Lignognathus setosus & 11 & 7.6 \\
\hline & & Trichodectes canis & 4 & 2.7 \\
\hline & & Total & 144 & \\
\hline
\end{tabular}

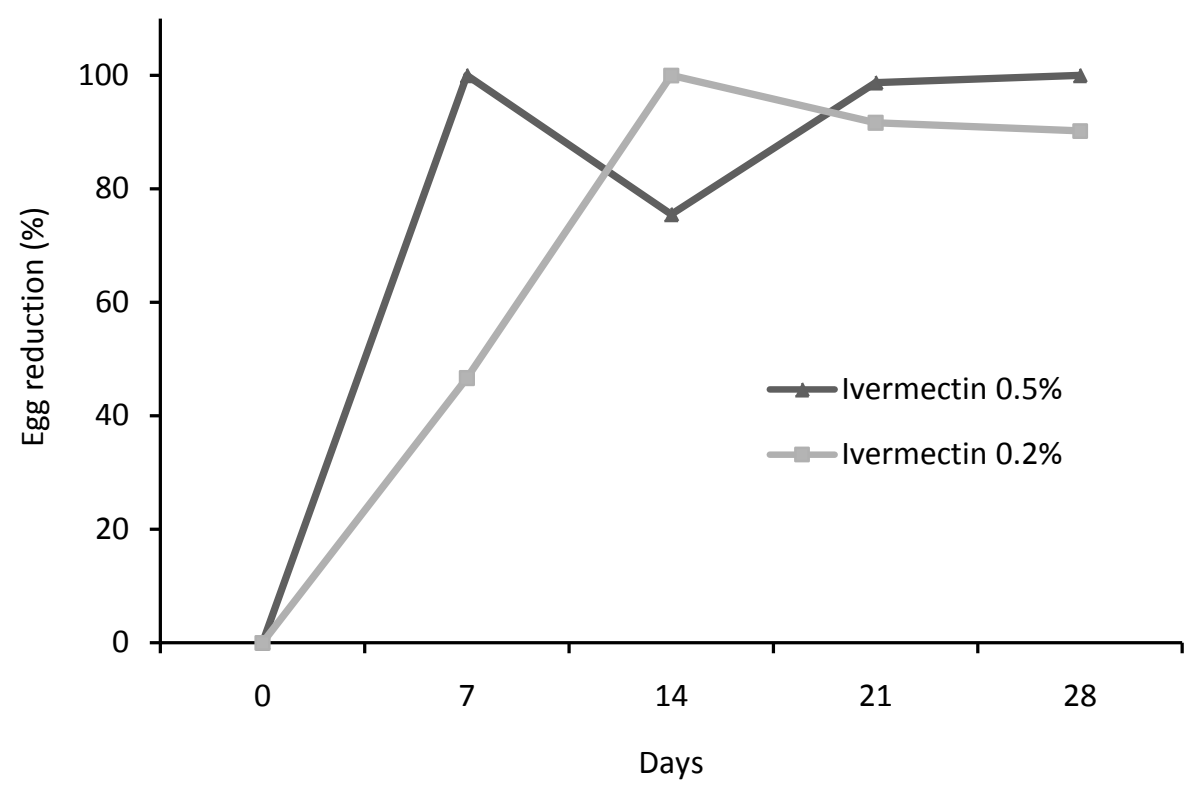

Figure 1. Anthelmintic efficacy of two pour on formulations of ivermectin in the egg reduction of Toxocara spp. in stray dogs.

dogs are launched at lower levels and formulations of IVM with a different excipient may exerta different efficacy percentage.

Interpretation of the results, taking into account study limitations and assesment of the current state of knowledge in the context of study results and other evidence were also considered.

As was observed, it seems that the $0.5 \%$ formulation of ivermectin is neccesary to remove a higher percentage of Ascarids and Ancylostoma spp., as well as flea infestations, but both formulations are equally effective against lice. However, the IVM administration in dogs may show a toxic effect if it passes the hematoencephalic barrier and reaches the central nervous sytem, a possibility that may increase depending of the dose used. However, it is well known that only certain races of dogs (Collie, Old English sheep dog, Doberman, German Shepherd 


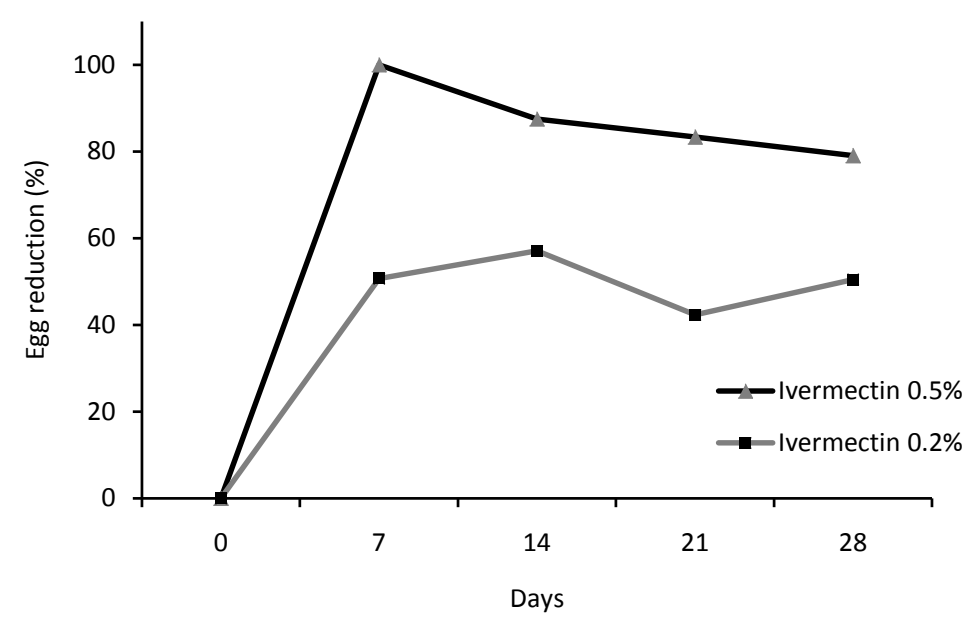

Figure 2. Anthelmintic efficacy of two different formulations of ivermectin in the egg reduction of Ancylostoma caninum in stray dogs.

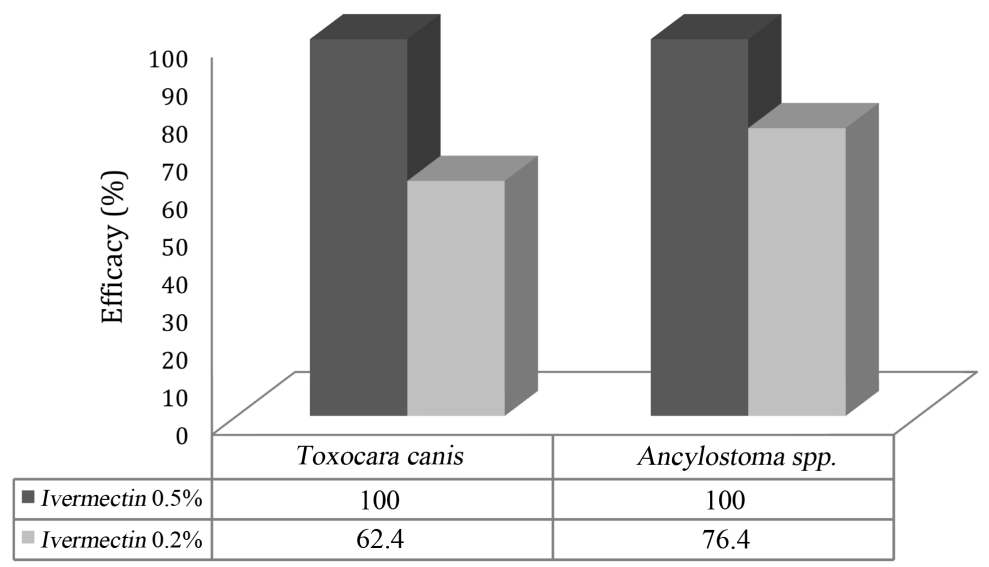

Figure 3. Efficacy percentage of two commercial compounds against adult intestinal parasites after single pour-on treatment in naturally infected dogs. No evaluations against Taenia taeniaeiformis and Toxascaris leonina were carried out since very few specimens of these parasites were recorded.

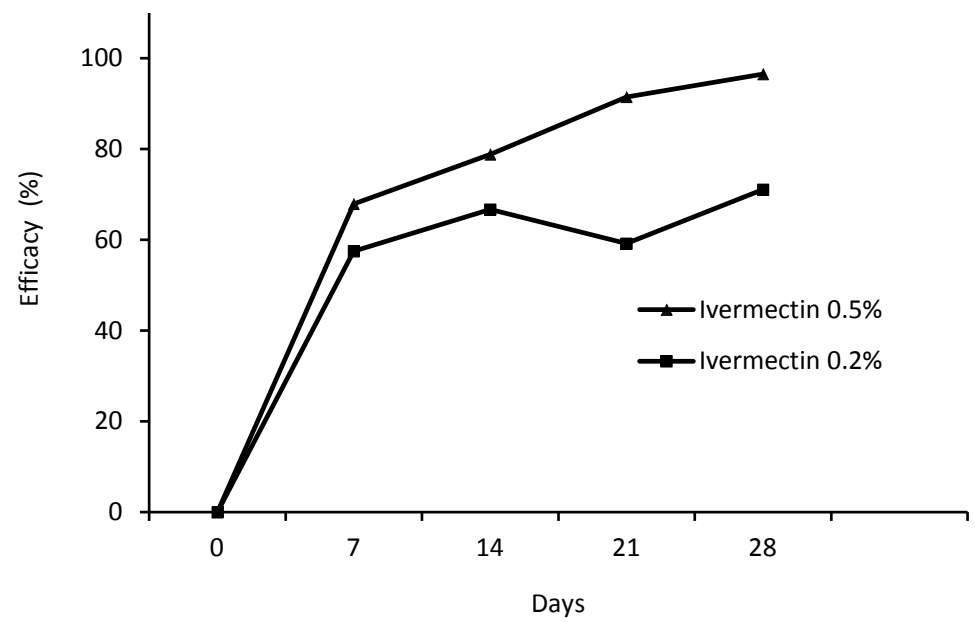

Figure 4. Comparison of the efficacy of two pour-on ivermectin formulations on the flea reduction in stray dogs. 
or their breeds), are susceptible to this toxic effect. Here it is important to mention that no adverse effects were observed after the treatment of the experimental dogs with both drugs, and the physical condition of treated animals was clearly improved at the end of the experiment.

Sueur et al. [26] mentioned that pour-on aplications requires that the treated animal not be bathed for the 24 hours after the treatment in order to make sure to the active ingredient can penetrate the skin.

Even though the experimental groups had an equal number of male and female dogs, it was not possible to carry out a statistical analysis since the number of parasites was too high or too small and this could produce a confusing effect which does not really show if males are affected with parasites more frequently or in greater proportion than females.

With the regard to weight it is well known than puppies between 2 to $5 \mathrm{~kg}$. show higher parasite EPG burden of ascarids and as the animals grow in age and weight the presence of Ancylostoma EPG is more frequently observed. In the present study this relationship was clearly noted.

\section{Conclusions}

Ivermectin at $0.5 \%$ showed better percentages of efficacy than the $0.2 \%$ formulation either in egg reduction or in the elimination and intestinal parasites as well as in the case of fleas. Both compounds showed $100 \%$ efficacy against lice.

Further studies should be conducted to determine if there is any toxicity in the use of pour-on presentations of these ivermectins on dogs since the available data up to now is limited.

\section{Acknowledgements}

The study is supported by Laboratorios Salud Animal, S.A de C.V, Mexico to the Internal Comitee for Animal Care and Use of Animals for Experimentation-Mexico, for approval to carry out the study.

\section{References}

[1] Beck, W., Boch, K., Mackensen, H., Wiegand, B. and Pfister, K. (2006) Qualitative and Quantitative Observations on the Flea Population Dynamics of Dogs and Cats in Several Areas of Germany. Veterinary Parasitology, 137, 130-136. http://dx.doi.org/10.1016/j.vetpar.2005.12.021

[2] Kozen, E., Sevimli, F.K., Birdane, F.M. and Adanir, R. (2008) Efficacy of Eprinomectin against Toxocara canis in Dogs. Parasitology Research, 102, 397-400. http://dx.doi.org/10.1007/s00436-007-0776-4

[3] Snyder, D.E., Wyseman, S., Cruthers, L.R. and Slone, R.L. (2011) Ivermectin and Milbemycin Oxime in Experimental Adult Hearthworm (Dirofilaria immitis) Infection in Dogs. Journal of Veterinary Internal Medicine, 25, 61-64. http://dx.doi.org/10.1111/j.1939-1676.2010.0657.x

[4] Ahmad, N., Qaqbool, A., Saeed, K., Ashraf, K. and Qamar, M.F. (2011) Toxocariasis, Its Zoonotic Importance and Chemotherapy in Dogs. The Journal of Animal \& Plant Sciences, 21, 142-145.

[5] Beck, W. and Panchev, N. (2010) Zoonosis Parasitarias. 1ra. Edition, SERVET, Zaragoza.

[6] Yeruham, I., Rosen, S. and Hadani, A. (1989) Mortality in Calves, Lambs and Kids Caused Severe Infestation with Cat Flea Ctenocephalides felis felis (Bouché, 1835) in Israel. Veterinary Parasitology, 30, 351-356. http://dx.doi.org/10.1016/0304-4017(89)90105-2

[7] Dryden, M.W. (1933) Biology of Fleas of Dogs and Cats. Pract. Vet., 15, 569-579.

[8] Gunn, A. and Pitt, S.J. (2012) Parasitology an Integrated Approach. Willey-Blackwell, Oxford.

[9] Azad, A.F. (1990) Epidemiology of Murine Thyphus. Annual Review of Plant Biology, 35, 553-569. http://dx.doi.org/10.1146/annurev.en.35.010190.003005

[10] Taylor, M.A., Coop, R.L. and Wall, R.L. (2007) Veterinary Parasitology. 3rd Edition, Blackwell Publishing, Oxford, 717.

[11] Obiukwu, M.O. and Onyali, I.O. (2006) Comparative Efficacy of Ancylol, Ivomec, Mebendazole, and Piperazine against Ancylostoma caninum in Experimentally Infected Pups. Animal Research International, 3, 540-544.

[12] Ashraf, K., Rafique, S., Hashmi, H.A., Maqbool, A. and Chaudhary, Z.I. (2008) Ancylostomosis and Its Therapeutic Control in Dogs. Journal of Veterinary and Animal Sciences, 1, 40-44.

[13] Khayatnoury, M.H., Garedaghi, Y., Arbati, A.R. and Khalili, H. (2011) The Effect of Ivermectin Pour-On Administration against Natural Heterakis gallinarum Infestation and Its Prevalence in Native Poultry. American Journal of Ani- 
mal and Veterinary Sciences, 6, 55-58. http://dx.doi.org/10.3844/ajavsp.2011.55.58

[14] Borges, F.A., Silva, H.C., Buzzulini, C., Soares, V.E., Santos, E., Oliveira, G.P. and Costa, A.J. (2008) Endectocide Activity of a New-Long Action Formulation Containing 2.25\% Ivermectin $+1.25 \%$ Abamectin in Cattle. Veterinary Parasitology, 155, 299-307. http://dx.doi.org/10.1016/j.vetpar.2008.04.019

[15] Hellmann, K., Heine, J., Braun, G., Pandesova, R. and Svoboduva, V. (2011) Evaluation of the Therapeutic and Preventive Efficacy of 2.5\% Moxidectin / 10\% Imidacloprid (Advocate ${ }^{\circledR}$, Bayer Animal Health) in Dogs Naturally Infected or at Risk of Natural Infection by Dirofilaria repens. Parasitology Research, 109, 77-86. http://dx.doi.org/10.1007/s00436-011-2404-6

[16] Snyder, D.E. and Wyseman, S. (2012) Dose Confirmation and None-Interference Evaluations of the Oral Efficacy of a Combination of Milbemycin Oxime and Spinosad against the Dose Limiting Parasites, Adult Cat Flea (Ctenocephalides felis) and Hookworm (Ancylostoma caninum) in Dogs. Veterinary Parasitology, 184, 284-290. http://dx.doi.org/10.1016/j.vetpar.2011.11.067

[17] Suarez, G., Alvarez, L., Castells, D., Correa, O., Fagiolino, P. and Lanusse, C. (2013) Relative Bioavailability and Comparative Clinical Efficacy of Different Ivermectin Oral Formulations in Lambs. BMC Veterinary Research, 9, 2734. http://dx.doi.org/10.1186/1746-6148-9-27

[18] Fagbemi, B.O. (1982) Effect of Ctenocephalides felis Infestation on the Performance of West African Dwarf Sheep and Goats. Veterinary Quarterly, 4, 92-95. http://dx.doi.org/10.1080/01652176.1982.9693846

[19] Bresciani, K.D.S., Freitas, D., Buzzulini, C., Chechi, C., Costa, J.P. and Oliveira, G.H.N. (2004) Effect of a 3.5\% Ivermectin + Abamectin Association with Weight Gain of Nelore Calves Kept on Pasture. XXIII World Buiatrics Congress, Quebec, 11-16 July 2004, 26-27. Center for Research in Animal Health, Intervet.

[20] Rodríguez, D.C., Steckelberg, A., Lopes, W.D.Z., Santana, I.F., Martins, J.R. and Borges, F.A. (2005) Actividade anti-Helmíntica da associaçäo Ivermectina $2.25 \%$ + abamectina $1.25 \%$ comparativamente a diferentes endectocidas em bovinos e efeito no desenvolvimento ponderal. A Hora Veterinaria, 25, 27-30.

[21] Costa, A.J. and Docentel, A.J. (2004) Atividade endectocida de una inovacao quimioteràpica (Ivermectina + abamectina): Resultados de 12 avaliçäo experimentais. Revista Brasileira de Parasitologia Veterinária, 13, 171-177.

[22] Garg, R., Kumar, K.A., Yadav, C.L. and Banerjal, P.S. (2007) Duration of Anthelmintic Effect of Three Formulations of Ivermectin (Oral, Injectable and Pour-On) against Multiple Anthelmintic-Resistant Haemonchus contortus in Sheep. Veterinary Research Communications, 31, 749-755. http://dx.doi.org/10.1007/s11259-007-0054-z

[23] Mandal, S.C. (2006) Veterinary Parasitology at a Glance. International Book Distributing Company, Lucknow, 203 p.

[24] Jacobs, D.E., Arakawa, A., Courtney, C.H., Gemmell, M.A., McCall, J.W., Myers, G.H. and Vanparijs, O. (1994) World Association for the Advancement of Veterinary Parasitology (W.A.A.V.P.) Guidelines Forevaluating the Efficacy of Anthelmintics for Dogs and Cats. Veterinary Parasitology, 52, 179-202. http://dx.doi.org/10.1016/0304-4017(94)90110-4

[25] Marchiondo, A.A., Holdsworth, P.A., Green, P., Blagburn, B.L. and Jacobs, D.E. (2007) World Association for the Advancement of Veterinary Parasitology (W.A.A.V.P.) Guidelines for Evaluating the Efficacy of Parasiticides for the Treatment, Prevention and Control of Flea and Tick Infestation on Dogs and Cats. Veterinary Parasitology, 145, 332344. http://dx.doi.org/10.1016/j.vetpar.2006.10.028

[26] Sueur,C.L., Bour, S. and Schaper, R. (2010) Efficacy of a Combination of Imidacloprid 10\%/Moxidectin 2.5\% Spot on (Advocat ${ }^{\circledR}$ for Dogs) in the Prevention of Canine Spirocercosis (Spirocerca lupi). Parasitology Research, 107, 14631469. http://dx.doi.org/10.1007/s00436-010-2022-8 